\title{
Influence of pedoclimatic factors on grapevine performance and berry ripening: Preliminary results of Chardonnay grown in Friuli Venezia Giulia region, Italy
}

\author{
L. Bavaresco ${ }^{1}$, J. Lemaignen ${ }^{2}$, E. Neethling ${ }^{2}$, C. Squeri ${ }^{1}$, and C. Coulon-Leroy ${ }^{2}$ \\ ${ }^{1}$ Department of Sustainable Crop Production, Pomology and Viticulture Section, Università Cattolica del Sacro Cuore, 29122 \\ Piacenza, Italy \\ ${ }^{2}$ ESA, International Vintage Master, Department of Viticulture and Oenology, Ecole Supérieure d'Agricultures, 55 rue Rabelais, \\ Angers 49007, France
}

\begin{abstract}
The concept of terroir is widely used in the wine industry, and many studies are undertaken to better understand the influence of local terrain features on produced wines. In this context, this study monitored nine Chardonnay plots in the Fruili wine region of Italy to gather information on grapevine growth and berry ripening. The study objective was to define viticulture potentialities allowing to identify future strategies for the production of a "single vineyard" Chardonnay wine at the Vie di Romans estate, Italy. During the growing season of 2017, relations were studied between terrain features and field observations on vine phenology and grape ripening. Stem water potential and gas exchange measurements were also effectuated. Results show that there are significant differences between the studied plots. Earliness of the grapevine cycle between the plots has been less evident to determine than the variation in berry characteristics. The latter were linked with identified pedoclimatic units, but the effect of the cultural practices should not be overlooked. The study should be perceived as a first monitoring campaign, highlighting the important differences between study plots. Further investigation in the following seasons should give a more accurate perception of individual plot characteristics and their impacts.
\end{abstract}

\section{Introduction}

In wine producing regions, the concept of terroir is highly important as it relates wine quality and style with the geographical origin in which the grapes are grown. Within the complex interaction between physical and biological factors, the impacts of viticulture strategies and decision making are very significant. To that end [1] summarized the two pillars of this concept as natural and human factors, detailing the importance of cultural and economic contexts of a vineyard. The particular characteristics are given by the climate (i.e. including both spatial and temporal variability), the soil and the vine water uptake conditions which are key factors in understanding the terroir effect on grape and wine quality. Indeed, the importance of the vine water status in the determination of the terroir perception in the final product has been shown in many studies [2,3]. These studies highlight its importance on vine vigour, berry weight and the sensorial characteristics of wines.

This study aims to explore the specific context of grape growing in the Friuli Plain region. In 2011, the surface area in Friuli Venezia Giulia was around 20,000 ha, placing the region at the $12^{\text {th }}$ position in Italy [4]. In 2016, regional wine production represented $1,856,000 \mathrm{hL}$, which is $3.71 \%$ of national production [5]. The production is spread over 3 DOCG, 8 DOC and 2 IGT. Around 1,500 estates are present, with an average vineyard area of 2 ha, where $80 \%$ have less than 10 ha [6]. Traditional local varieties are cultivated along with international ones. The monitored vines of the study belong to the Vie di Romans estate, located on the Friuli Isonzo DOC, which counts for around $12 \%$ of the total DOC and DOCG production of the region (Fig. 1).

From a morphological point of view, Friuli Venezia Giulia has a complex terrain. The region is composed by the Friulan plain, some subalpine low hills composed by marly and sandy soils, and finally the high-altitude terrains in the north (Carnic Alps and occidental side of the Julian Alps). Numerous rivers cross the territory from North to South, and Friulan vineyards are mostly defined by their position between the Adriatic Sea and the Alps. On the North, more elevated vineyards are protected from heat stress by the regular presence of clouds, blocked by the mountain, bringing the possibility to acquire a full phenolic maturity without an uneven increase in sugars. On the other side, the plain vineyards can benefit from the maritime influence of the Adriatic Sea, which moderates the diurnal temperature variation and permits to have a more stable climate.

In this study, the observed vineyards belong to the Vie di Romans estate, in the Isonzo plain that represents the eastern part of the Friulan plain (extending to the Veneto region on the west), and shares the same origin and morphological characteristics. The plain is constituted by alluvial deposits that have occurred during the Quaternary Era. From a lithological viewpoint, the northern hills are constituted by marlstones and siltstones belonging to the Flysch formation, whereas the eastern reliefs by 


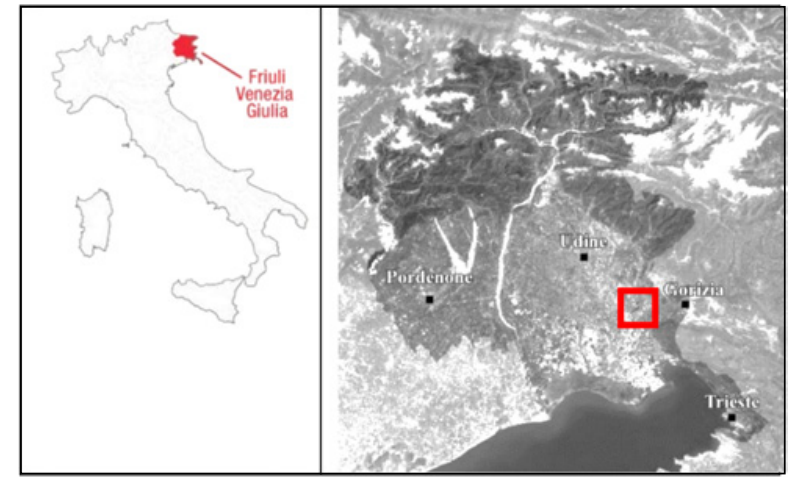

Figure 1. Location of the studied vineyard area in Fruili Venezia Giulia, Italy.

the intensely karstified limestone of the Karst plateau. The alluvial cover lays on limestone or on silicicclastic turbidites. The bedrock deepens increasingly and regularly from North to South and towards the coast it occurs at a depth of $250 \mathrm{~m}$ [7]. In Mariano del Friuli, Vie di Romans vineyards are planted on soils with lightly different characteristics. These soils are parallel to the Versa river on the North. The "base layer" soil of the Isonzo plain is older and coarser, mostly calcareous, originated by the alluvial cones of the Isonzo and Natisone rivers. It is an alkaline, well-drained soil, with a high proportion of coarse elements. On top of this soil, more recent sediment deposits were carried by the Versa river, and the phenomenon appears more intense closer to the river. These soils are cambisols and contain a high fraction of clay and silt [8].

\section{Material and methods}

Nine Chardonnay plots have been monitored (Fig. 2) during the 2017 growing season. Plots are located under a $1.6 \mathrm{~km}$ radius from the winery. The average altitude of the vineyard plots is between $27 \mathrm{~m}$ and $33 \mathrm{~m}$ above sea level. Plots present variability in the way they are cultivated: area of the characterized plot, clone selection, rootstock choice, age of the vine, training system (Guyot, double cordon or simple cordon), row orientation. Thus, it is important to mention that this work has been done in a functioning winery and has the aim of describing and analysing differences in a real context of production. However, it has been decided with the project sponsor to limit the vegetal material variability by only working on the Chardonnay clone and rootstock combinations of $548 \times \mathrm{SO}_{4}$ or $548 \times 101^{-14}$.

\subsection{Agronomic measures}

For each plot, 4 blocks of 5 vines were identified and tagged (i.e. 20 vines/plot). To avoid external environment influences, vines were chosen inside the plots. The principal phenological stages have been considered reached when $50 \%$ of the counted measures presented a value superior or equal to the phenological stage value, and have been noted: "mid_Bb" (BBCH scale $\mathrm{n}^{\circ}$ 9) for budbreak, "mid_Fl" (BBCH scale $\left.\mathrm{n}^{\circ} 65\right)$ for the flowering, "mid_Ve" (BBCH scale $\mathrm{n}^{\circ} 83$ ) for the veraison and (BBCH scale $n^{\circ} 89$ ) for the picking date.

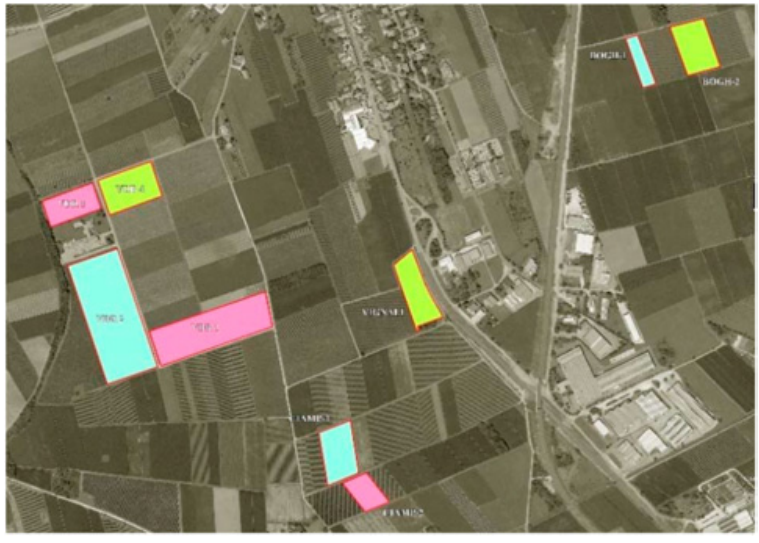

Figure 2. Map of the plots under study (light green: guyot $\times \mathrm{SO}_{4}$, light blue: cordon $\times \mathrm{SO}_{4}$, pink: cordon $\times 101^{-14}$ ).

Stem water potential was measured during the day, when photosynthesis is active and climatic demands are high, with a Scholander chamber. In a plot, measures were done on 8 basal leaves belonging to a primary shoot, on the shady side in the afternoon. Reference leaf is the $5^{\text {th }}$ basal leaf. Leaf gas exchanges were measured at two key periods: after fruit set and prior to veraison. For each plot, 10 leaves were sampled. Sampled leaf is the $6^{\text {th }}$ leaf from basal node. Measurements were performed on clear days, between $10.30 \mathrm{am}$ and $12.30 \mathrm{pm}$, using an Infrared Gas Analyser (IRGA) model LC $i$-SD produced by ADC BioScientific Ltd.

From fruit set to veraison, classic maturity measurements were undertaken, including: fruit weight, sugar concentration in must observed by refractometry, total acidity evolution, grape juice $\mathrm{pH}$ evolution, tartaric and malic acid concentrations of the juices. The idea was to use standard tools and instruments easily available for an operating winery. In addition, a grape-derived aromatic compound analysis was performed by an external laboratory (Polo Lab, Oderzo, Italy) using GC-MS protocols.

\subsection{Climate measures}

Seasonal climate data was provided by three meteorological stations iMetos 2 from Pessl Instruments, strategically located over the vineyard. Soil samples have been realized on the 9 plots on the 27th and 28th of June 2017. Depending on the area of the plot, between two and five excavations were performed, trying to reach the geological base layer. GPS location of the excavation was recorded and integrated in a Google map (Fig. 2). For each location, the soil matter of the pedological horizons was sampled separately, and the horizon depth was measured. The proportion of coarse elements was calculated after filtering the sample with a $2 \mathrm{~mm}$ hole diameter sieve. Fine matter fraction was analysed by an external laboratory (Laboratorio Analisi Cicognani, Forli, Italy). Data provided includes a soil texture analysis (sands, silts and clays) and a soil chemical composition analysis. Analyses were done following the methodology described in "Metodi Ufficiali di Analisi Chimica dei Suoli", officially approved by a governmental order from the Ministro per le Politiche Agricole in 1999. 


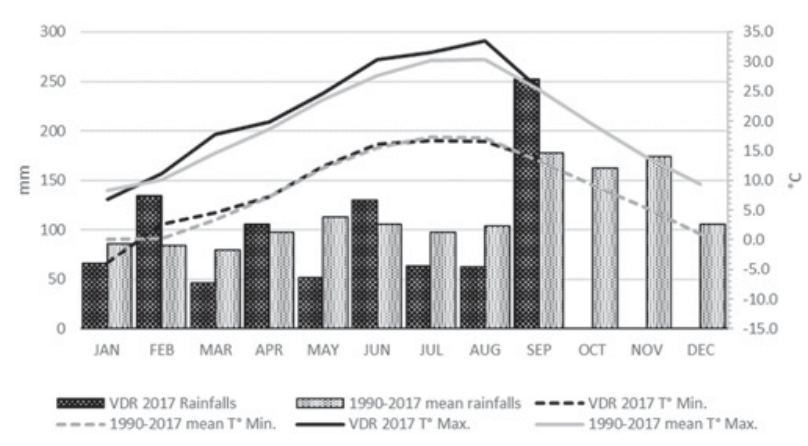

Figure 3. Vie di Romans (VDR) 2017 growing season climate conditions compared to the average conditions for 1990-2017.

\section{Results and discussion}

\subsection{Climate conditions and variability}

As it has been observed in numerous northern hemisphere viticulture areas, the 2017 climate conditions were quite particular. Compared to mean rainfall totals and temperatures for the 1990 to 2017 period recorded by the nearest meteorological station at the city of Gradisca d'Isonzo (Fig. 3), the 2017 vintage presented a warmer and rainier end in winter, a warmer and identically rainy spring and a warmer and drier summer.

During the month of February, rainfalls increased by $60 \%$ compared to 1990-2017 average, but decreased by $42 \%$ in March. May, July and August were drier than average. At the end of the study, September data was partially available, but projections tend to show a usually rainy month. Taking a closer look to the minimal temperatures, 2017 vintage follows the average tendency, with the notable exception of February and March, when minimal temperatures were higher by $2.4{ }^{\circ} \mathrm{C}$ and $1.1^{\circ} \mathrm{C}$ respectively. On the other hand, maximal temperatures were constantly recorded at a higher level from February to September, with maximal variations observed in March, June and August $\left(+3.2^{\circ} \mathrm{C},+2.8^{\circ} \mathrm{C}\right.$ and $+3.1^{\circ} \mathrm{C}$ respectively). In addition to this general description of the vintage, it must be mentioned some specific climatic perturbations that impacted vine growth and vineyard production. On the night of 20 April, temperatures dropped down (i.e. to $-2.0^{\circ} \mathrm{C}$ ) and caused intense frost damages in some plots of the estate. Surface water aspersion and warming candles were used to limit the damages. On the other side, September was a rainier month than average, while temperatures were normal.

The Fig. 4 show the comparison of 2017 data, recorded by three meteorological stations acquired by the estate. Located at the edges of a $1 \mathrm{~km}$ long triangle, the estates stations allow to see in detail the local climate of the different plots. "VDR" station has constantly monitored more rainfalls from March to August, and remains with a high level in September. Cumulated rainfalls for "Ciampagnis" and "Maurus" stations are similar during the growing period, at the notable exception of September when "Maurus" registered higher rainfalls. Regarding the temperatures, it is noticed that the three meteorological stations registered very close values till the late spring, both for minimal and maximal air temperature. Summer has seen a pronounced differentiation between the plots, with the lower temperatures remaining relatively close for all, whereas maximum air temperature was rising

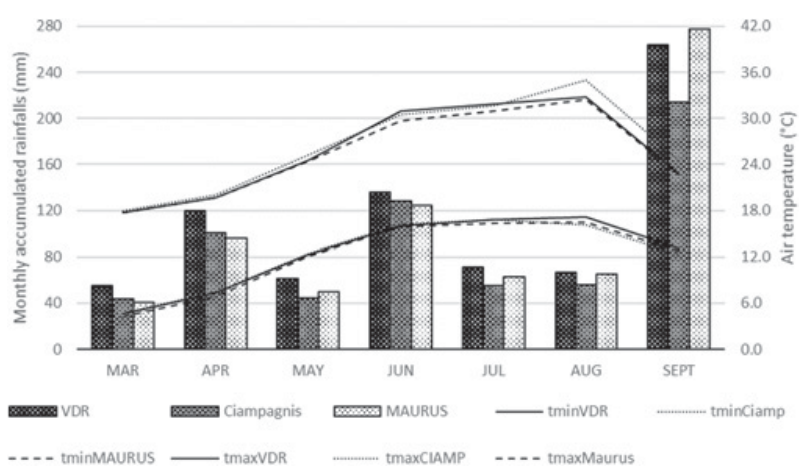

Figure 4. The "VDR", "CIAMPAGNIS" and "MAURUS" meteorological stations data comparisons for the 2017 vintage.

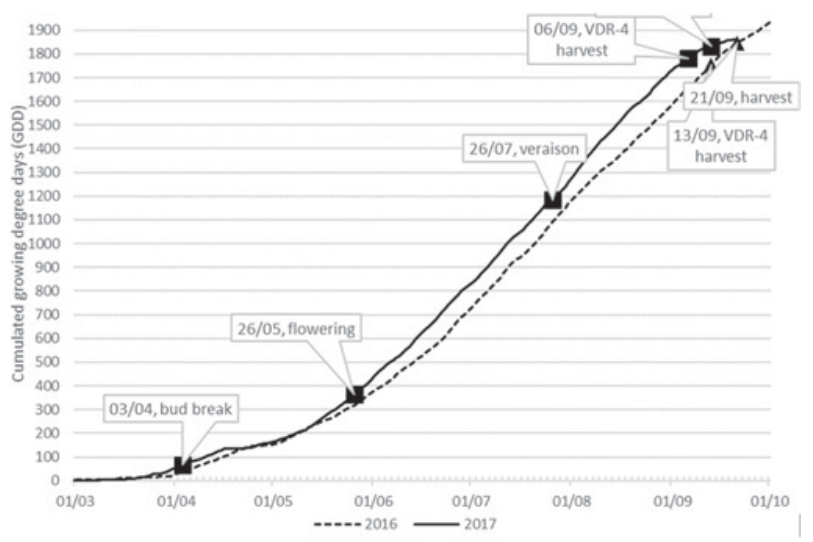

Figure 5. Comparison of the main phenological stages dates between 2016 and 2017, in relation with accumulated GDD.

for "VDR" and "Ciampagnis" stations. In September, temperatures fall abruptly, and "Ciampagnis" remains with the highest maximal air temperature. Consequently, thermal excursion remained similar each month till the late spring, when it increased for "VDR" and "Ciampagnis" which is the plot with the highest maximal thermal excursion registered in August $\left(18^{\circ} \mathrm{C}\right)$. If the monthly cumulated rainfalls are not significant to differentiate between stations, temperatures indicate that "Maurus" station registered lower values for minimal and maximal temperatures. The same situation occurred in 2015 and 2016, identifying "Maurus" area as a cooler vineyard area.

\subsection{Vine phenology}

The 2016 vintage has seen a cooler growing period, expressed by lower accumulated GDD than in 2017 in every segment of the year (Fig. 5). Comparing the main phenological dates between the two vintages, it appears clearly that 2017 was an earlier vintage, with harvest done around one week prior than in 2016. Cumulated GDD for the two harvests were similar (1770 GDD for VDR-4, and 1840 for other plots). Unfortunately, 2016 data is not available for the other main phenological stages, but it could be supposed that all stages were occurring as earlier as harvest. In 2017, "Mid_Bb" occurred between 02/04 and 04/04, which illustrates that climatic conditions prior to bud break were quite similar between the different plots. It has been calculated that the mean mid_Bb date for the 2017 vintage was 03/04 and has required 67 GDD. Projected on the cumulated growing degree days of 2016 , this value is reached between 07/04 and 09/04. This tends 
to confirm that 2017 growing period was earlier due to higher temperatures during the first months of the year. "Mid_Fl" was reached between 24/05 and 25/05/2017.

However, it is noticeable that some plots have seen a very quick and uniform flowering, such as CIAMP-1 and VDR-4, while others were more variable over time, such as VDR-1 and VIGNALI. This variability may be linked to the extreme climatic conditions that occurred one month prior to flowering (i.e. the spring frost event on 20/04). The mean of mid_Fl was 25/05/2017 and required around 350 GDD. In 2016, this value was reached between the 28/05 and 29/05. "Mid_Ve" occurred between 23/07 and 25/07/2017, with a mean date of 23/07 and heat requirements of 1165 GDD. This value was reached at the end of July or beginning of August in 2016, which confirms the observed earliness in 2017. "Harv" was performed on 06/09 for VDR-4, 13/09 and $14 / 09 / 2017$ for the remaining plots. Maturation curves illustrated that the technologic profile of grapes was not homogeneous at picking time. The different commercial dates of picking result of strategic considerations based on weather conditions at the beginning of September. From 06/09 to 13/09/2017, it rained all days and picking was not possible.

\subsection{Grape ripening}

\subsubsection{Technological parameters}

During the fruit development and ripening period, the average berry weight varies strongly between plots. It increases quickly during the early stages, followed by a lag phase of around two weeks and a new intense growing period until the estimated veraison date at the end of July. A late berry weight increase is observed during the first part of September and can be attributed to intense rain episodes, which delayed commercial harvest dates.

Measured from the beginning of August until commercial harvest dates, total soluble content follows a similar trend between the different plots. A pronounced increase is observed during the first half of August, then stabilize and initiate a slight decrease during the first weeks of September. In relation with the increase of berry weight at the same period, it could be due to water accumulation in the fruit, resulting in a dilution process. It is notable that berries with lower total soluble contents at veraison remain with lower contents at harvest. This homogeneous trend leads to believe that the combination between soil and plant material defines the sugar synthesis efficiency, while climate influences the total amount produced.

Total acidity and $\mathrm{pH}$ values follow a correlated pattern during the late ripening period. Total acidity decreases during the first half of August and then progressively stabilized at a value near of $5 \mathrm{~g} / \mathrm{L}$ (eq. tartaric acid). $\mathrm{pH}$ values increased during August by 0.11 units per week, and reached a peak at the beginning of September between 3.40 and 3.60 units. The total acidity variability between plots at veraison tends to reduce over time, while $\mathrm{pH}$ values remain quite unequal. Plots with lower $\mathrm{pH}$ values at veraison have also lower values at harvest time. Tartaric and malic acid concentrations have been measured at three intervals (02/08, 18/08 and harvest). Malic acid concentration decreased strongly from the onset of veraison to mid-August, and then decreased slowly till harvest date. Total degradation of malic acid was around
$4 \mathrm{~g} / \mathrm{L}$ between the beginning of August and picking date. At the beginning of August, tartatic acid concentrations were in the same range than malic acid concentrations, but decreased at a notable slower pace till picking date. Values remain quite variable at harvest, ranging from $5.04 \mathrm{~g} / \mathrm{L}$ to $5.76 \mathrm{~g} / \mathrm{L}$.

\subsubsection{Impact of climate and soil conditions on grape ripening}

To identify the role of climatic conditions on berry development and ripening, principal component analysis was performed. It puts in relation the berry weight, the total soluble content, the total acidity concentration and $\mathrm{pH}$ values with cumulated precipitation, cumulated growing degree days and cumulated solar radiations for the different plots on 02/08/2017 and 31/08/2017. The mean clay percentage for each plot has also been integrated to better reflect the differences between plots.

Two main components explain $83.6 \%$ of the data collected. Temperatures, expressed by the GDD value, and to a lower extent solar radiation, have the most impacting effect on the total soluble content and $\mathrm{pH}$, while the average berry weight is positively correlated with the accumulated rainfalls and the clay percentage in the soil. Thus, it has been proposed to gather the plots between homogeneous pedoclimatic units, with the same clay proportion and climatic pattern during the growing season (i.e. GDD, solar radiation and cumulated rainfalls).

Group A (BOGHIS-1 and BOGHIS-2): low clay percentage in the soil, low accumulated rainfalls, low GDD and high solar radiation. However, changes in berry characteristics during the late maturation is contrasted. BOGHIS-1 cordon-trained vines grapes are constantly heavier, richer in total soluble content, with a higher $\mathrm{pH}$ and a lower total acidity than BOGHIS-2 Guyot-trained vine grapes.

Group B (CIAMP-2 and VIGNALI): low clay percentage in the soil, low accumulated rainfalls, high GDD and high solar radiation. Evolution of the berry technological characteristics is also contrasted between cordon-trained vines and Guyot trained vines, at the exception of the average berry weight which decreases homogeneously. Due to harvest timing, it was not possible to separate CIAMP-1 and CIAMP-2 grapes, and it has been decided to ignore values registered at this stage.

Group C (CIAMP-1): high clay content in soil. Evolution of the berry technological characteristics are like the ones observed on CIAMP-2, at the exception of the berry weight which is higher than CIAMP-2 ten days after veraison and lower two weeks' prior the harvest.

Group D (VDR-1 and VDR-4): high clay percentage in the soil, high accumulated rainfalls, high GDD and high low solar radiation. In comparison with the mean values of all plots, evolution of berry technological characteristics is relatively similar between VDR-1 and VDR-4. Ten days after veraison they present high total soluble content, low $\mathrm{pH}$ and low total acidity, while average weight is variable; 40 days after veraison values are homogeneous for all characteristics; and at harvest time values are comparable at the exception of average berry weight which is higher for VDR-1.

Group E (VDR-3 and VDR-2): medium clay soils, high accumulated rainfalls, high GDD and low solar 
radiations. For the two plots, average berry weight increases in similar proportion till 31/08 and differentiate clearly after, total acidity remains among the lowest during the period, while $\mathrm{pH}$ was relatively high and total soluble content was average to low in comparison with other plots. Variability inside the group tends to define VDR-2 grapes as more concentrated (higher $\mathrm{pH}$ and lower weight) and with a lower $\mathrm{pH}$.

One-factor analyse of variance was performed for values registered the $02 / 08$ and the $31 / 08$. Results show that the pedoclimatic groups above mentioned do not necessarily fit with the berry characteristics. This may illustrate the importance of taking in account the perennial parameters (training system, rootstock, age of the vine) to characterize more precisely the plots under study. To test the contribution of different training systems on soils and the variability of berry parameters during ripening, onefactor analyses of variance was performed. Hence, they do not take in account the climate impacts.

Berry weight: for Guyot trained vines, grapes grown on loamy fine sand soils (LFS) were consistently heavier than grapes grown on sandy loam soil (SL), while no difference was found for cordon trained vines. The clay / sand ratio in the soil profile was also confronted to berry weight. Grapes from Guyot-trained vine tend to be heavier with lower ratios, while no consistent result was found for the cordon-trained vines.

Total soluble solids content: Guyot-trained vines grown on LFS soils have a lower ${ }^{\circ} \mathrm{Bx}$ level at veraison than the ones cultivated on SL soils. This situation is not statistically evidenced for other dates. For these vines, it is also evident that grapes grown on low clay/sand ratio soils have a lower ${ }^{\circ} \mathrm{Bx}$ degree, on $02 / 08$ and $31 / 08$. No difference was found on harvest date but this is probably due to a lack of samples (VDR-4 was harvested one week earlier). On cordon-trained vines, no statistically significant differences were found between LFS and LS soils. Differences are found testing the clay/sand ratio, but do not express a direct relation by increasing number. Therefore, interpretation of the results is limited.

$\mathrm{pH}$ : grapes from Guyot-trained vines on LFS soils present a lower $\mathrm{pH}$ than grapes from Guyot-trained vines on LS soils at maturity $(31 / 08,13 / 09)$. Difference are not found for cordon-trained vines. Lower $\mathrm{pH}$ are found for grapes produced from Guyot-trained vines on a low clay/sand ratio during all the monitored period. Differences were found for cordon-trained vines but are not related to a regular increase in the clay/sand ratio.

Total acidity: 10 days after veraison, significant difference is found between LFS and SL soils for Guyottrained vine grapes. This difference is not visible for other sampling dates. For these vines, total acidity is positively related with a low clay/sand ratio on $02 / 08$ and $31 / 08$, but not at harvest date. Cordon-trained vines have a higher acidity on SL soils than on LFS soils after veraison (02/08) and at harvest time (13/09). Sand/clay ratio permit to found significant differences which are not related with a regular increase with the ratio value.

In conclusion, the soil influence represented by texture has a visible impact on berry characteristics, better highlighted for the Guyot-trained vines. The lack of visibility in the Cordon-trained vines may result of the different rootstock varieties. Regarding the non-volatile compound analysis, it has not been possible to sample the different plots at the same technological maturity point. Therefore, it is difficult to estimate the real aromatic potential of each plot that may have been of interest for the wine production strategy in 2017. However, the performed non-volatile compound analysis puts in light some differences such as the low concentrations founded for VDR-1 and VDR-4, compared with the high values for the BOGHIS-2, CIAMP-2, VDR-3 and VIGNALI plots.

\section{Conclusion}

The present study has permitted to gather a large amount of data regarding vine behaviour, berry characteristics and soil attributes of nine Chardonnay plots, located in the Friulan region (Italy). Combined with the analysis of climate conditions during the 2017 growing season, the various measurements are contributing to enrich the estate database about the Chardonnay plots and their viticulture potentialities. The monitoring of the phenological stages and the analyse of the grape quality permitted to identify important distinctions between the nine plots. Some plots appear to have a lower "expression" than others, which means they have reached lower total soluble contents, with higher total acidity levels associated, a low $\mathrm{pH}$ and a similar grape-derived volatile compounds concentration (BOGHIS-2, VIGNALI). On the other hand, some plots produced grapes having a particular behaviour, such as VDR-4 which was constantly reported with the highest total soluble content but remain in the average concerning acidity, despite a low $\mathrm{pH}$. It was possible to identify a significant impact of soil composition on the juice characteristics of Guyot-trained vines grafted on $\mathrm{SO}^{4}$ rootstock. Differences were significant among the cordontrained vines but it was not possible to isolate the effect of the rootstock from the one of the soil. For both cases, it should not be overshadowed that slightly different climate conditions between the plots, registered by the meteorological stations, may introduce a bias in the measurement of the soil factor influence.

Due to the geographical position of the Vie di Romans estates, in the plain and without any notable topographic event, nor the proximity of water masses such as a lake or river, or screens like woods, it seems logical that the rainfall pattern, average air temperatures and solar radiation are comparable between the stations. However, data show subtle variations that permit to qualify the plots by the combination of climatic parameters (GDD, cumulated rainfalls, cumulated solar radiation) and clay content. This allows to define 5 groups of pedoclimatic units. However, behaviour of the vine inside a unit is variable, and the present data has not allowed to isolate the impact of viticulture practices on the internal variability. Finally, the analysis of the complex soil-vine-climate interactions defining the concept of "terroir" would not have any interest if not followed by a sensorial analysis. A separate and uniform micro-vinification process for each plot, with grapes having reached a similar technological maturity defined by a simple index such as minimal Brix grade, would permit to link the information gathered during the growing season with an evaluation of the perceived wine quality. This would be another significant step in the long but exciting path that leads to the definition of a Chardonnay "cru" wine for the Vie di Romans estate. 


\section{References}

[1] C. Van Leeuwen, G. Seguin, J. Wine Res. 17, 1 (2006)

[2] D.I, Jackson, P.B. Lombard, Am. J. Enol. Vitic. 4, 409 (1993)

[3] E. Vaudour, J. Wine Res. 13, 117 (2002)

[4] ISTAT (2010) http://dati-censimentoagricol tura.istat.it/Index.aspx

[5] I numeri del vino (2017) http://www. inumeridelvino.it/2017/03/produzione-divino-in-italia-2016-primo-aggiornamentoistat.html
[6] Consorzio DOC FVG (2015) http://www . consorziodocfvg. it/le-doc-del-fvg/doc-eigt-del-fvg/

[7] Progetto GEP (2014) http: //www .gepgis .eu/it/ wp-content/uploads/2014/01/wp_6_isonzo_ plain_it.pdf

[8] ARPA FVG (n.d.) http://www.ersa.fvg.it/ tematiche/suoli-e-carte-derivate/i-suolidel-friuli-venezia-giulia/livello-didettaglio-1-50-000-1-100.000/Gorizia/ mappe/unita?q=3.jpg 